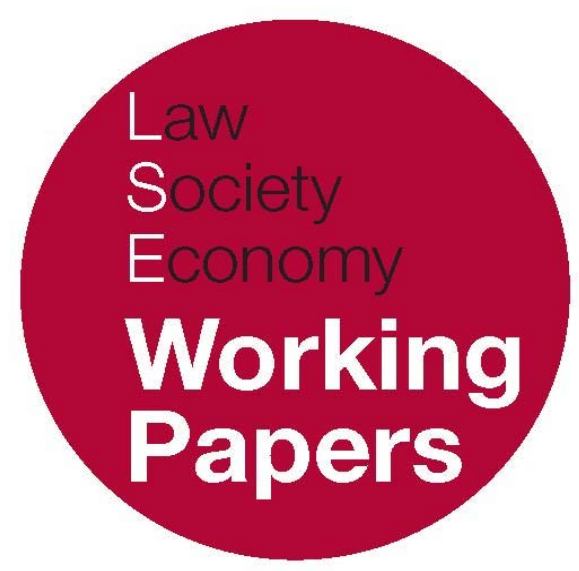

\title{
Learning from Regulatory Disasters
}

\author{
Julia Black \\ LSE Law, Society and Economy Working Papers 24/2014 \\ London School of Economics and Political Science \\ Law Department
}

This paper can be downloaded without charge from LSE Law, Society and Economy Working Papers at: www.lse.ac.uk/collections/law/wps/wps.htm and the Social Sciences Research Network electronic library at: http://ssrn.com/abstract=2519934.

(C) Julia Black. Users may download and/or print one copy to facilitate their private study or for non-commercial research. Users may not engage in further distribution of this material or use it for any profit-making activities or any other form of commercial gain. 


\title{
Learning from Regulatory Disasters
}

\author{
Julia Black ${ }^{*}$
}

\begin{abstract}
Regulatory disasters are catastrophic events or series of events which have significantly harmful impacts on the life, health or financial wellbeing of individuals or the environment. They are caused, at least in part, by failures in, or unforeseen consequences of, the design and /or operation of the regulatory system put in place to prevent those harmful effects from occurring. Regulatory disasters are horrendous for those affected by them. Because of that we have an obligation to learn as much from them as we can, notwithstanding all the well-known challenges related to policy and organisational learning. The article focuses on five distinct and unrelated regulatory disasters which, although they occurred in apparently unrelated domains or countries, contain insights for all regulators as the regulatory regimes share a common set of elements which through their differential configuration and interaction create the unique dynamics of that regime. In the regulatory disasters analysed here, these manifest themselves as six contributory causes, operating alone or together: the incentives on individuals or groups; the organisational dynamics of regulators, regulated operators and the complexity of the regulatory system in which they are situated; weaknesses, ambiguities and contradictions in the regulatory strategies adopted; misunderstandings of the problem and the potential solutions; problems with communication about the conduct expected, or conflicting messages; and trust and accountability structures.
\end{abstract}

\footnotetext{
* Professor of Law and Pro Director for Research, London School of Economics and Political Science. This article was given as the Sir Frank Holmes Memorial Lecture in April 2014 when the author was the Sir Frank Holmes Visiting Professor of Public Policy at the Victoria University, Wellington. I am grateful to those attending the lecture and participating in subsequent discussions for their comments and to Judy Kavanagh and Peter Mumford for their comments. All the usual responsibilities remain my own. This paper has been published in (2014) 10(3) Policy Quarterly 3-11.
} 


\section{INTRODUCTION}

In 2010 an explosion in the Pike River mine in New Zealand killed twenty nine people and, on the other side of the world, a blowout at the Macondo oil well killed eleven people and caused major environmental damage as four million barrels of oil spilled into the Gulf of Mexico. In 2005 a cloud of petrol vapour from the Buncefield tank storage depot in the south of England exploded over two major motorways early on a Sunday morning, which if it had happened at any other time could have caused significant loss of life. In 2008 the Royal Bank of Scotland (RBS), one of the UK's largest banks, was rescued from collapse by a government bail-out of $£ 46 \mathrm{bn}$, a contributor to and casualty of the global financial crisis. In the mid-late 1990 s to early 2000 s poor building practices led to significant losses for homeowners in New Zealand caused by leaky buildings. Estimates of the losses range to as high as NZ $\$ 11.3 \mathrm{bn} .{ }^{1}$

These disastrous events from opposite sides of the globe seem to be disparate. Some are systemic failures across an industry, others are single events; some are low probability, high impact events, others high probability and low impact if measured as the impact per individual affected at a single point in time, but high impact if assessed on an aggregate basis across a number of individuals and a period of time. What they have in common is that they are all regulatory disasters: a catastrophic event or series of events which have significantly harmful impacts on the life, health or financial wellbeing of individuals or the environment, caused, at least in part, by a failure in the design and /or operation of the regulatory regime put in place to prevent their occurrence.

Regulatory disasters can be a particular form of policy disaster. Policy disasters have been defined as the disastrous unintended consequences which occur as the direct consequence of poor intentional choices by top political decision-makers. ${ }^{2}$ Regulatory disasters may also be seen as a particularly acute form of a policy blunder. King and Crewe, for example, define a 'policy blunder' as:

an episode in which a government adopts a particular course of action in order to achieve one or more objectives, and as a result largely or wholly of its own mistakes, either fails completely to achieve those objectives or does achieve them but at a totally disproportionate cost, or else does achieve them but contrives at the same time to cause a significant amount of 'collateral damage' in the form of unintended or undesired consequences. ${ }^{3}$

\footnotetext{
1 This is the estimate provided by PWC, see online at http://www.dbh.govt.nz/UserFiles/File/News/WHRS/pdf/PWC-weathertightness-estimating-cost-fullreport.pdf.

2 Dunleavy, P. (1995),'Policy Disasters: Explaining the UK's Record', Public Policy and Administration 10(2), 52.

${ }^{3}$ King, A and Crewe, I (2014), The Blunders of Our Governments (London: Oneworld) p.4.
} 
However, the scale of their consequences means that 'regulatory disasters' are more than just 'policy blunders'. They include disasters caused by 'judgement calls' as well as poor design and implementation and, as used here, 'regulatory disasters' deliberately excludes 'political disasters' - those which are disasters for the reputation or continued existence in power for the politicians or regulators involved. Many of the regulatory disasters highlighted here are also political disasters, but a policy which is purely or mainly a disaster in political terms is not included.

Regulatory disasters are also distinct from policy disasters in that they occur in a particular sub-field of public policy, and indeed need not be confined to the state at all: they result from the unintended and unforeseen consequences of the design and / or operation of a regulatory system and its interactions with other systems. As such they can arises from poor decisions by politicians in the design of the regulatory regime and / or political influences on its operation, and / or poor decisions and practices by regulatory officials themselves within a system that may be either well or poorly designed. Regulation, or regulatory governance, is the organised attempt to manage risks or behaviour in order to achieve a publicly stated objective or set of objectives; a regulatory system consists of the (sometimes shifting) set of interrelated actors who are engaged in such attempts and their interactions with one another and the dynamic institutional and organisational environment in which they sit. Thus regulatory disasters also differ from public service delivery disasters, as they do not involve the delivery of services to the public directly organised by a government department, agency or authority; or that are provided on behalf of, financed and regulated by government, ${ }^{4}$ unless those disasters arise at least in part from failures in the design and / or operation of the regulatory system to which that public service, such as a hospital, is subject.

Regulatory disasters are horrendous for those affected by them. Because of that, we have an obligation to learn as much from them as we can, notwithstanding all the well-known challenges related to policy and organisational learning. For regulators, probing the reasons for the disaster, even if it occurred in another country, or in a different regulatory domain, can provide insights for the evaluation of their own systems. They can also provide useful leverage for persuading political overseers of the need for change. Regulatory systems can have a significant number of 'latent' failures which only become apparent on the occurrence of a particular major event, such as an explosion or financial collapse, or through the recognition of an accumulation of a number of smaller events, such as individual deaths, smaller scale pollution events or individual financial losses. These are the disasters 'which are waiting to happen'. Other disasters were not foreseen, but neither may they have been reasonably foreseeable, or involve 'black

${ }^{4}$ Contrast Dunleavy P, Tinkler J, Gilson C, and Towers E, 'Understanding and Preventing Public Service Policy Disasters', LSE Public Policy Group, available at http://www.academia.edu/2871538/. 
swan' events - what had been seen as low probability albeit high impact events. ${ }^{5}$ Nonetheless, the inquiries that often follow a disaster, even if it is a 'black swan' event, often reveal systemic problems within the regime which have hence far gone unnoticed by regulators, or unheeded by key policy actors.

Analysing the causes and nature of regulatory disasters also enables us to understand more about the nature of regulation itself. Although regulatory disasters often occur in apparently unrelated domains or countries, they can in fact contain lessons for all regulators, as regulatory regimes share a common set of elements which through their differential configuration and interaction create the unique dynamics of that regime. In the regulatory disasters analysed here, these manifest themselves as six contributory causes, operating alone or together:

- The incentives on individuals or groups;

- The organisational dynamics of regulators, regulated operators and the complexity of the regulatory system;

- Weaknesses, ambiguities and contradictions in the regulatory strategies adopted;

- Misunderstandings of the problem and the potential solutions;

- Problems with communication about the conduct expected or conflicting messages;

- Trust and accountability structures.

The article focuses on five distinct and unrelated regulatory disasters: the construction of 'leaky buildings' in New Zealand in the late 1990s-2000s, the explosion at the Buncefield chemical plant in the UK in 2005, the events leading up to the bail out of the Royal Bank of Scotland in the UK in 2008, the Macondo oil well blow out at the Deepwater Horizon oil rig in the Gulf of Mexico in 2010, and Pike River mining tragedy in New Zealand, also in 2010.6 These are chosen because they are uncontroversial examples of regulatory disasters - significantly adverse impacts on human health, financial position or the environment which arose from the design and operation of a regulatory regime intended to manage the very risks which materialised. They also have the advantage that each was subject to extensive investigation by an independent body established specifically to inquire into the causes of the disaster, thus providing a wealth of factual information. Whilst there are always inherent biases in any investigation, those which followed each of these disasters have not been significantly criticised as biased or 'captured' by any particular interest.

${ }^{5}$ Taleb, N (2007), Black Swan: The Impact of the Highly Improbable _London: Penguin)

${ }^{6}$ Note that the lecture also included examples from the Mid-Staffordshire hospital inquiry in the UK, but this is omitted here for reasons of space: see Report of the Mid Staffordshire NHS Foundation Trust Public Inquiry (2013) HC947. 


\section{THE INCENTIVES ON INDIVIDUALS OR GROUPS}

In the aftermath of any disaster, there are normally calls from politicians and the public for individual liability to be imposed, for there to be some 'heads to roll'. However, the role of individuals in causing or contributing to regulatory disasters is not straightforward. In some cases individuals may be a direct cause of a failure, for example 'rogue traders' such as Nick Leeson, whose trading activities brought down Barings Bank in 1995. However, there is a complex interaction between individuals and the organisational context in which they are operating, which makes separating out individual action difficult. In the regulatory disasters analysed here, individuals are often the proximate cause, but their actions are only an element in a series of interactions or events contributing to the disaster.

In particular, the organisational context can produce conflicting incentives which affect individual behaviour. The Pike River report found that individuals in the workforce were operating in a context in which production was more important than safety, for example. ${ }^{7}$ Conflicts of interests can exist within regulators as well as regulated firms. In the case of Deepwater Horizon, regulators were responsible both for awarding licences for deep water drilling and collecting the associated royalties, and for ensuring safety and environmental protections. The drive for royalty income was such that a culture of revenue production dominated safety or environmental concerns, to the extent that some offices developed a practice of taking 'benefits in kind' instead of royalties, leading to serious charges of abuse of government authority and even criminal misconduct. ${ }^{8}$ In addition, individual pay and reward schemes were linked to the speed in which officials issued licences, distorting balanced decision making, particularly with respect to environmental impacts. ${ }^{9}$ As many regulatory activities are performed through individuals, it is not surprising that the decisions, actions and inactions of individuals play a role in producing regulatory disasters. But just to focus on individuals alone is to miss the significance of how their actions are governed by and interact with the broader organisational and institutional context in which they are situated.

\footnotetext{
${ }^{7}$ Ibid, p.12.

${ }^{8}$ National Commission on the BP Deepwater Horizon Oil Spill and Offshore Drilling, Deepwater - the Gulf Oil Disaster and the Future of Offshore Drilling, Report to the President (2011) (hereafter Deepwater Horizon report), p.77. For a full discussion of the regulatory environment see chapter 3 .

${ }_{9}^{9}$ Deepwater Horizon report, p.82.
} 


\section{ORGANISATIONAL DYNAMICS, INSTITUTIONAL CONTEXT AND SYSTEM COMPLEXITY}

Organisations are mechanisms which translate individual actions into collective action by enabling them to be sustained over time. ${ }^{10}$ The organisational systems, processes and dynamics of both regulators and regulated operators (regulatees) have played a significant role in all the regulatory disasters analysed here, as have the dynamics of the inter-relationships between them within the regulatory system as a whole. The internal dynamics of organisations are in turn affected by their broader institutional context, including the wider regulatory system. For firms, this is usually the markets in which they are operating. For regulators it includes their legal mandate and powers, their governance and accountability structures, the political context and their informal and formal relationships with other regulatory actors.

That context can drive organisational dynamics and priorities in direct ways. In the case of Pike River, for example, the report found that whilst the 'drive for production' was a normal feature of coal mining, Pike River was in a particularly stressed economic situation as it was in 'start up' mode: it had only one mine, which was producing far less than had been forecast, and it was seeking to gain market credibility in order to raise capital. ${ }^{11}$ In such circumstances, directors and executive managers paid insufficient attention to health and safety risks. The market context can also have a systemic effect across an industry, with significant implications for how a regulatory regime operates in practice. For example, in the case of New Zealand's 'leaky buildings' disaster, the Hunn report found that skill levels in the building sector had been declining, and that the changing practices within the market meant that builders were no longer overseen by professionals, such as surveyors and architects, as they had been in the past. ${ }^{12}$

For regulators, it is the political and legal context which has most bearing on their organisational structures, processes and decision making. Often, the legal mandate and powers that regulators have is deficient in one or more ways. In the case of Pike River, the legal framework for health and safety regulation was criticised as too fragmented: those who issued licences to mine were not mandated to look at health and safety, so licences to mine were given without any scrutiny of health and safety. The regime may not include all of the risks that the activity poses: in the case of the Buncefield explosion, the report found that under the UK regulatory regime, societal risks (such as to health and safety of those living in the vicinity of the site) were not taken into account in the land use and planning decisions made with respect to high hazard sites. The legal mandate may also be

\footnotetext{
${ }^{10}$ Reed, M (2003), 'The Agency/Structure Dilemma in Organization Theory: Open Doors and Brick Walls' in Knudsen, C and Tsoukas, H, The Oxford Handbook on Organization Theory (Oxford: OUP).

${ }_{11}$ Pike River report, Executive Summary.

12 Report of the Overview Group on the Weathertightness of Buildings to the Building Industry Authority (2002) (hereafter Hunn Report), p.9.
} 
such that it creates significant conflicts of interest for the regulator. In the case of the Deepwater Horizon disaster, the Minerals Management Service was responsible for licensing and collecting royalties, and for environmental and health and safety regulation, and operated in a political context in which oil exploration, and preserving the royalties from that exploration, were the dominant concerns. ${ }^{13}$ Conflicting incentives and objectives in legal mandates often stem from the political compromises brokered between conflicting parties which are then embodied in the governing legislation. As the Report to the President noted: 'From birth, MMS had a built-in incentive to promote offshore drilling in sharp tension with its mandate to ensure safe drilling and environmental protection.'14 Furthermore, governments themselves can have vested interests that conflict with other goals. It is a notable theme throughout the regulatory disasters arising from the extraction industry (mining, oil drilling) that the conflicts of interest created by the government's interests in mining or drilling for natural resources can override its role in preserving the environment or making decisions about the health and safety. ${ }^{15}$

Legislators also impose a business model on regulators through their decisions on funding. Those funded directly from government are prey to cuts in resources, which has an obvious impact on their ability to perform their role. ${ }^{16}$ The Report to the President concluded that the MMS had to pursue safety regulation on a 'starvation diet' due to Congress's unwillingness to grant it appropriate resources. ${ }^{17}$ In the case of Pike River, for example, the government had reduced funding to the inspectorate and merged it with the broader Department of Labour. As a result, there were only two mining inspectors for the whole of New Zealand. But business models can be imposed in other ways. Both environmental and health and safety regulators in the UK, for example, are under a legal requirement to recover the costs of their inspections. The report into the Buncefield explosion found that the legal requirement to recover costs 'can have an unwanted effect upon regulatory activities and the relationship between the [regulators] and duty-holders' and 'induce tensions in the relationship with site operators'. ${ }^{18}$

Even where the legal mandate is clear and a regulator has a full range of powers, the political context and accountability structures can have a significant impact on how the regulator interprets it mandate and uses its powers. In the case of the MMS, it tried more than once to amend the regulatory provisions to introduce the requirement for a safety case and other reforms, but was continually

\footnotetext{
${ }^{13}$ Deepwater Horizon Report, chapter 3.

${ }^{14}$ Ibid, p.56.

15 Pike River report, vol II, p.267; Deepwater Horizon Report, p.85.

16 See Deepwater Horizon report, chapter 3, for a discussion of the depletions of the MMS's resources.

${ }^{17}$ Deepwater Horizon Report, p.72.

18 The Report of the Buncefield Major Incident Investigation Board into the Policy and Procedures of the Health and Safety Executive's and the Environment Agency's role in regulating the activities on the Buncefield site under COMAH Regulations (2012) (hereafter Buncefield report), p.66.
} 
blocked by industry, Congress and the Office of Management and Budget. ${ }^{19}$ In the case of leaky buildings, the Hunn report reported that:

Some territorial authorities and building certifiers hold the view that the certification process is constrained by a desire expressed by the BIA [the Building Industry Authority] to building officials that any change to the process must avoid putting inflationary pressure on building costs. ${ }^{20}$

Overall, it concluded that 'Political influence may be compromising standards'. ${ }^{21}$ In the UK, although the Financial Services Authority had a broad legal mandate and a wide set of powers to regulate banks and other financial institutions, the report into the failure of the Royal Bank of Scotland found that the FSA had felt constrained from intervening too closely in RBS's business model by politicians' ambitions to preserve the City of London's position as an international financial centre. $^{22}$ In the US, royalty income from oil exploration was a highly lucrative source of revenue; ${ }^{23}$ in such a context, industry's voice was allowed to frustrate attempts by the MMS to enhance regulation of their activities and the agency was never granted the political autonomy to resist them. ${ }^{24}$

Whilst the political and legal context has a role to play in shaping organisational processes, cultures and decision making, a striking feature of all the regulatory disasters analysed here is the central role played by failures of governance and leadership within organisations, in both regulators and regulated firms. Critical are the skills and training of personnel, the resources of the organisation, weaknesses in leadership, and governance, including failures to manage risks strategically. Also striking are the consistent failures of organisations, particularly regulatory organisations, to coordinate in the operation of the regulatory system, failures which are exacerbated the more complex the system.

With respect to internal failings of organisations, there are four central findings which are common both to regulators and regulated operators.

First, and most obviously, culture matters. Organisations are internally complex and informal norms often dominate formal rules in the way activities are carried out and decisions are made. As a result, safety rules can be overridden when employees think they are unnecessary, as in Pike River. ${ }^{25}$ Or the culture drives decisions. In the case of the MMS, for example, environmental scientists

\footnotetext{
${ }^{19}$ Deepwater Horizon report, pp.71-73.

${ }^{20}$ Hunn Report, p.19.

${ }^{21}$ Ibid p.22

22 FSA, The failure of the Royal Bank of Scotland: Financial Services Authority Board Report (2011), p.262 (hereafter RBS report).

${ }_{23}$ At the time the MMS was created, royalties for oil drilling were the second highest source of revenues for the US government: Deepwater Horizon report, p.63.

${ }^{24}$ Deepwater Horizon report, chapter 3.

${ }_{25}$ Pike River report, p.19.
} 
within MMS stated that their managers believed that all environmental impact assessments should result in a 'green light' for drilling. ${ }^{26}$

Secondly, the training, skills and expertise of personnel matters: organisations may simply lack people with appropriate expertise. This is a common feature in all the disasters, but it is notable that lack of training and expertise is often a more striking feature for regulators than it is for regulatees. This is frequently due to resources: disparities in pay between the regulator and industry can make recruitment difficult. ${ }^{27}$ However it can also be because those at the top of the organisation do not value specialist expertise, as in the case of the MMS in the US. ${ }^{28}$ Alternatively, organisations may have the expertise but those experts are not called upon to look at the appropriate problems, as in the case of the supervision of major hazard chemical sites in the UK, where environmental specialists were not called on at the appropriate times. The Buncefield investigation also found that experts from different disciplines can find it difficult to work together productively, and specialists may have little empathy or time for generalists, all of which can lead to conflicts over priorities and oversights. ${ }^{29}$ In contrast, generalists may disregard the calls for resources made by specialists, as they cannot see the need for them. The impact this has depends on where the expert or generalist is within the organisation. One feature of Pike River was that the line managers were generalists and so did not understand how to inspect mines, even limiting the travel budgets of the inspectors to inspect mines on the North Island on the basis that the resources came out of the South Island's budget. ${ }^{30}$

Thirdly, organisational failures usually come from the top. A central finding is the failure of leadership, in both regulators and regulated firms. For example, in the case of Pike River, the investigation found that 'The board did not provide effective health and safety leadership and protect the workforce from harm.' 31 The necessary information simply was lost as issues moved up the organisation, and as a result the Board could not assess or challenge assurances that had been given to it by management. An analysis of the failures of the boards of financial institutions in the wake of the financial crisis found exactly the same. ${ }^{32}$ Boards can also be distracted: in the case of Pike River, the Board was distracted by the financial and production pressures that confronted the company; in the case of RBS, by the gains to be made from the activities it was pursuing. Regulators can be equally distracted: in the case of the FSA, the Board had focused most of its attention on dealing with legacy issues from the previous regime, and on retail and insurance regulation. Analysis of Board minutes for the years leading up to RBS's rescue

\footnotetext{
${ }^{26}$ Deepwater Horizon report, p.82.

${ }^{27}$ See for example, Pike River report, p.29, 274-5; RBS report, p.24.

${ }^{28}$ Deepwater Horizon report, pp.77-78.

${ }^{29}$ Buncefield report, p.30.

${ }^{30}$ Pike River report, p.277.

31 Pike River report, p.18; see also Hutter, B (2001) Regulation and Risk: Occupational Health and Safety on the Railways (Oxford: OUP).

32 Senior Supervisors Group, Risk Management Lessons from the Global Banking Crisis of 2008 (October 2009); OECD, Corporate Governance and the Financial Crisis: Key Findings and Main Messages' (June 2009).
} 
found that the Board had devoted very little time to considering prudential regulation issues. ${ }^{33}$ In the case of Pike River, the absorption of the mining inspectorate into the generalist health and safety inspectorate, which was itself part of a much larger Department of Labour, meant that the Department did not focus sufficiently on health and safety issues. ${ }^{34}$

Fourthly, organisations often take the path of least resistance, and as a result can fail to manage risks strategically. In the case of major hazard regulation (which for these purposes is taken to include financial supervision of systemically important banks), attention can focus more on the events that are 'happening here and now' rather than risks that events 'may happen in the future'. The Board report into the supervision of RBS found that the Board focused more on legacy issues and retail misselling which demanded immediate attention, and as a result did not pay attention to prudential risks which were seen to be remote. In the context of more traditional major hazard industries, the Buncefield report provided a useful reminder that 'Previous major incidents around the world such as Texas City, Longford (SE Australia) and Piper Alpha remind us that the task of controlling major hazard risks can become insidiously subverted by undue attention being paid to the less organisationally demanding issues of occupational safety'. ${ }^{35}$ This is not a problem confined to regulators: in both the case of RBS and BP, neither focused adequately on high impact, low probability events. ${ }^{36}$

The complexity of the regulatory system can also be a key contributory element. In any regulatory system, multiple regulators will often have to interact, but for varying reasons fail to do so effectively, or even at all. As a result, interorganisational failures between regulators can be as significant as internal failures in regulators and regulatees in contributing to regulatory disasters. For example, in the case of Pike River, the investigation found that each regulator involved interpreted its mandate narrowly and did not share information with the other agencies involved. ${ }^{37}$ In the case of leaky buildings, the Hunn report found that split responsibilities for approving building consents and issuing certificates led to confusion about roles, responsibilities and processes. ${ }^{38}$ In the case of Deepwater Horizon, the overlapping jurisdictions of the MMS and the US Coastguard led to a requirement to continually renegotiate informal interagency agreements over an extended period and in effect expand the MMS's jurisdiction, contributing to its under-resourcing. ${ }^{39}$

Furthermore, the different mandates of regulators may lead them to have differential priorities, which is a problem when they are meant to be jointly

\footnotetext{
33 RBS Report, p.266.

34 Pike River report, p.29.

35 Buncefield report, Recommendation 22.

36 Deepwater Horizon report; RBS report, and see House of Commons Energy and Climate Change Committee, UK Deepwater Drilling - Implications of the Gulf of Mexico Oil Spill, HC 450-I, para 33.

${ }^{37}$ Pike River report, p.268.

${ }^{38}$ Hunn report, p.23.

${ }^{39}$ Deepwater Horizon report, p.76.
} 
regulating the same site or activity, particularly where each is operating a risk based system for allocating inspection resources. For example, in the case of Buncefield, the site had a lower priority for the Health and Safety Executive than it did for the Environment Agency. As a result, the HSE was slow to complete its assessment of the site, delaying the ability of the environment regulator to ask the firm to address particular issues. ${ }^{40}$ Although there was a memorandum of understanding in place between the two regulators, there was 'scant compliance' with it. Software incompatibility inhibited data sharing, communication was 'more a case of "copying in" colleagues in the other agency than proactive liaison'. ${ }^{41}$ Very commonly, there is also a lack of clarity about which agency has lead responsibility for which issues. 42

Finally, failures in oversight can contribute to the difficulties of system management: regulators can be subject to performance or accountability measures which impose conflicting priorities on them, as with the MMS in the US, or which are incapable of identifying weaknesses as they lack the expertise to do so, as in the case of Pike River, or do not see it as their role, as in the case of the BIA.

\section{REGULATORY STRATEGIES AND TECHNIQUES}

At the outset, regulatory disasters were differentiated from more general policy disasters as they involved the failure of a regulatory regime to manage the behaviour or risks that it was created to manage in order to achieve a broadly defined goal or set of goals. There is a wide array of regulatory techniques that can be used to achieve those goals, each with its own strengths and vulnerabilities. Each of the failures involved a different regulatory technique. In the case of Deep Water Horizon, regulation was highly prescriptive and expressed in legislation. Although the regulator had pressed Congress to revise the legislation to bring it up to date, this had not occurred. As a result, the deep water drilling techniques that the industry was using were in effect unregulated as they were simply not covered by the relevant legislation. ${ }^{43}$ In the aftermath of the disaster, the US government agreed to adopt a system akin to that used in Norway and the UK, often referred to as 'enforced self regulation' or management based regulation. In such systems, the safety systems and processes are not prescribed in legislation, rather the legislation sets an overall objective, such as 'a safe system of work', and the duty holder has to present its 'safety case' to the regulator for approval, setting out how it proposes to achieve that objective. This system was introduced in the UK as a result of the Robens Report in 1972,44 and forms the basis of New Zealand's

${ }^{40}$ Buncefield report, para 55.

${ }^{41} \mathrm{Ibid}$, para 72.

${ }^{42}$ Ibid, para 99, 124-5.

${ }^{43}$ Deepwater Horizon report, pp.71 and 75.

${ }^{44}$ Committee on Safety and Health at Work. (Robens Committee): Report and Papers (London: HMSO). 
health and safety regulation. ${ }^{45}$ It was widely praised by the US commission investigating the Deep Water Horizon disaster as the best system to use, and has since been adopted there. The UK also reassured itself of the strength of the regime in a Parliamentary review of the regulation of offshore drilling in the UK in the wake of the Deep Water Horizon disaster set up to see what lessons, if any, could be learned from it for the UK. 46

However, any strategy has an Achilles heel. One of the striking things about the regulatory failures relating to the supervision of banks and financial markets in the UK, and mines and buildings in New Zealand, is that each was an example, at least from a distance, of a textbook case of 'new regulatory governance' techniques. ${ }^{47}$ Management based regulation was used both in the case of the regulation of the mining industry in New Zealand, and the regulation and supervision of RBS (and other banks) in the UK. In the case of New Zealand, however, the Pike River commission argued that in translating the UK system for health and safety regulation to the New Zealand context, it implemented a 'light' version of the system which gave flexibility by focusing on the objectives to be achieved, but failed to supplement this with sufficient guidance or even prescription as to the minimum standards necessary, or sufficient engagement of the workforce in compiling the safety case. ${ }^{48}$ Management based regulation works well where management's incentives are sufficiently aligned with the regulators' goals - however, as the FSA's supervision of RBS showed, where they are not so aligned, the technique is vulnerable to failure.

In the case of the building and mining industries, New Zealand also pulled back from prescribing products or processes to setting performance standards, more often referred to in the UK context as 'outcomes focused' regulation. This strategy involves removing a great deal of prescription from the rules, whilst setting overall goals to be achieved. The Pike River report found that in getting rid of those provisions, the regulatory system lost what might be termed its 'institutional memory'. It commented:

The special rules and safeguards applicable to mining contained in the old law, based on many years of hard-won experience from past tragedies, were swept away by the new legislation, leaving mining operators and mining inspectors in limbo. ${ }^{49}$

45 See online at http://www.mbie.govt.nz/pdf-library/what-we-do/workplace-health-and-safetyreform/effective-regulatory-framework.pdf.

${ }^{46}$ House of Commons Energy and Climate Change Committee, UK Deepwater Drilling - Implications of the Gulf of Mexico Oil Spill, HC 450-I.

${ }^{47}$ On the UK system see Black, J (2012), 'Paradoxes and Failures: 'New Governance' Techniques and the Financial Crisis' (75)(6) Modern Law Review 1037.

48 Pike River report, Vol 2, p.252; see also Pike River: Report of the Independent Taskforce on Workplace Health and Safety (April 2013).

${ }^{49}$ Pike River report, p.32. 
Performance based or outcomes focused regulation places significant demands on both regulators and regulatees' judgement and expertise. However, complex systems of detailed rules can be just as demanding to implement and have the additional disadvantage of becoming easily outdated, as in the case of the regulatory regime for deep water drilling in the US. ${ }^{50}$ These contrasting examples highlight the care that has to be taken in designing a rules-based system, to ensure there is the right combination of principles or outcomes-focused norms and sufficient 'scaffolding' through more detailed guidance provisions to indicate to firms how to comply, and assure themselves and regulators that they have done so. ${ }^{51}$

A less commented-on regulatory technique, at least in the academic literature, is the art of monitoring and inspection. Whilst there is a considerable research on how to get regulated operators to comply with regulation, there is far less on how regulators can assure themselves, and others, that operators are or are not complying. However, a common feature across all the cases studied is poor monitoring strategies. In the case of Pike River, for example, inspections were on site, but did not involve wider audits of systems and processes, or assessments of firms' culture. In the case of RBS, in contrast, oversight focused too much on systems and processes, and not enough on the business model. It was also partial, focusing on some areas of risk, mainly retail operations where there were known concerns, but not others, notably capital adequacy, where the risks were seen as more remote (and where the supervisors had less experience). ${ }^{52}$ Similarly in Buncefield, the regulators were criticised for focusing on known defects rather than taking a strategic review of all the control measures in place, and focusing on lagging rather than leading indicators. ${ }^{53}$ The report recommended that there should be a 'clear line of sight' between the inspection plans and the strategic outcome sought'. ${ }^{4}$

\section{KNOWLEDGE, IDEAS AND UNDERSTANDINGS}

Regulation is a problem-based activity: 'society' in some form decides there is a problem, or that there is a risk of a problem in the future, and policy makers and regulators devise ways to address that problem. But how we identify something as a problem is contingent on what we value (and therefore what we think is under threat), and how we analyse problems and create solutions for them is contingent on our knowledge and understanding of the world, and our ideas of how it

\footnotetext{
51 Black, J (2008), 'Forms and Paradoxes of Principles Based Regulation' Capital Markets Law Journal 3(4), available at http://eprints.lse.ac.uk/23103/1/WPS2008-13.pdf.

51 Black, J (2008), 'Forms and Paradoxes of Principles Based Regulation' Capital Markets Law Journal 3(4), available at http://eprints.lse.ac.uk/23103/1/WPS2008-13.pdf.

52 RBS report, p.242.

${ }^{53}$ Buncefield report, para 97.

${ }^{54} \mathrm{Ibid}$, recommendation 6.
} 
operates. This applies to our understandings of regulatory disasters as it does to any other problem.

Knowledge, ideas and understandings are critical in the context of risk regulation. As noted above, operational drivers can be such that risks that are known, but considered low probability albeit high impact, are ignored not because they are not known about, but because a combination of assumptions about probabilities, understandings of impact and operational drivers means they are not prioritised for attention.

More problematic, perhaps, are the risks which are known but not recognised as important for the regulatory system. Low risks, in particular, may escape attention both in the design of the regulatory regime or its operation because their cumulative impact is not known, or at least not recognised in that particular regulatory regime. For example, the Buncefield report found that the UK's regime for major hazard regulation of chemical sites did not cover low risks which may have an incremental impact. Nor did it recognise societal risks, i.e. risks to those living near the site as opposed to those working on it. 55 Whilst the report recommended that planning decisions should take account of societal risk and the HSE is working on technical guidance on the issue, the UK Government has yet to introduce such a requirement. ${ }^{56}$ Some risks are just unknown, however. The explosion at Buncefield, for example, was a consequence of the ignition of a large cloud of vapour that was formed during the loss of petrol from a storage tank. The circumstances which led to the release of the vapour were predictable, but the consequences were not. The vapour release generated much higher pressures than would normally have been expected from a vapour cloud explosion, and exactly how or why the chemical reaction occurred was still unknown at the end of the investigation. ${ }^{57}$ Similarly, in the case of RBS, and indeed with respect to the global financial crisis more broadly, assumptions that had been made as to how markets would react in particular scenarios proved significantly misplaced, with risk events that had been anticipated to occur once in several lives of the universe were occurring every day. In this case the causes were social rather than chemical, and it is a moot issue as to whether they could have been predicted had different modelling techniques, and a different understanding of markets had been used. Nonetheless, we cannot always manage uncertainty - we cannot always prevent disasters arising from risks that we know exist but about which we do not have full knowledge, nor can we manage risks that we do not know about at all.

\footnotetext{
55 Ibid, para 146-7.

56 See online at http://www.hse.gov.uk/landuseplanning/societalrisk.htm.

57 Ibid, paras 19, 32, 51.
} 


\section{COMMUNICATION AND TRUST}

Finally, the last elements of regulatory regimes which play a role in contributing to disasters lie in the communication and trust (or lack thereof) that exists between regulators themselves, and between regulators and those they regulate, and between regulators and those to whom they are accountable.

With respect to communication, messages that different actors send as to the goals of the regulatory system may conflict. The Hunn report found, for example, that the forward to the guidance on compliance with the Building Act stated that the aim of the Act was to 'minimise compliance costs', but it was unclear whether this related to the administrative costs of compliance or to the overall cost of design and construction compliance. ${ }^{58}$ This is a particularly pertinent observation for the $\mathrm{UK}$, which has recently introduced a requirement for non-economic regulators to take into account 'economic growth' in the exercise of their functions. 59

Trust is also central to the operation of a regulatory system, but just what degree of trust is appropriate or 'optimal' is a difficult issue to manage in practice. Regulators may have long standing relationships with certain regulated firms, particularly large scale operators who are geographically fixed (mining operators in contrast to container ships, for example). Much research has found that regulators, either deliberately or less consciously, seek to build cooperative relationships with regulatees, and only to escalate enforcement action in response to the attitude of the regulatee and / or the scale of the incident. ${ }^{60}$ Although the US is often distinguished from other countries in this regard, it is worth noting that relationships between the MMS and the operators were also close, in some cases overly so. ${ }^{61}$ In all the examples analysed here, the reports criticised the regulators for being insufficiently interrogative of the information given to them by firms, too slow to take action once problems were identified, or not to have set out clearly when more formal action would be taken. ${ }^{62}$ In the case of RBS, regulators were simply too trusting. From mid-2006 onwards, the FSA's supervisors assessed firms against criteria relating to their management and controls, and whether it had dealt openly with the FSA. On the basis of these assessments it decided whether, and to what extent, a firm could benefit from a 'regulatory dividend'. ${ }^{63}$ The Royal Bank of Scotland was given a regulatory dividend in 2006-7, notwithstanding that relationships had in the past been highly fractious. ${ }^{64}$ In its report into the failure of RBS the review team declared that the concept of a regulatory dividend was 'flawed' and 'potentially dangerous'.65 It rewarded firms with less intensive

\footnotetext{
58 Hunn report, p.18.

${ }^{59}$ Deregulation Bill 2014, clause 61.

${ }^{60}$ Ayres, I and Braithwaite, J (1992) Really Responsive Regulation (Oxford: OUP).

61 Deepwater Horizon report, p.77.

62 Buncefield report, para 95; Hunn report p.21.

63 RBS report, p.257.

64 Ibid, pp. 257 and 242.

65 FSA, RBS report, p.242.
} 
supervision if they could demonstrate effective controls and displayed a degree of cooperation with the FSA 'that ought to have been a non-negotiable minimum'. It is worth noting that 'trust' may be resource-driven, however: the report also noted that the dividend may also have been awarded to enable supervisors to manage conflicting pressures with limited resources. ${ }^{66}$

\section{REGULATORY DYNAMICS AND POTENTIAL POINTS OF FAILURE}

Although the analysis here examines each element in isolation, in reality each element interacts with the others to produce the unique dynamics of any regulatory regime. But whilst each disaster is in many ways distinct, there are some common sources of failure which are observable irrespective of the domain being regulated. In fact, the points of failure are depressingly familiar and, most importantly, are common to both regulators and regulated operators. Within organisations, these are most often inadequate training and skills of front line staff, conflicting incentives or incentives which conflict with the goals of the regulatory regime, and poor leadership and management oversight. In addition, poor internal coordination and communication, for example between different types of experts, and weak coordination between the different regulators charged with managing the system, are all too common.

The disasters also illustrate the particular points of weakness of different regulatory techniques. For example, prescriptive regulation can quickly become outdated, but performance based or outcomes focused regimes requires a supporting scaffolding of guidance. Management-based techniques need to ensure that the goals of the regulator really are embedded in firms. In industries characterised by low probability, high impact events, they show that firms and regulators need to take care not to be overly distracted with managing the high probability, low impact events which are happening here and now. All the disasters also illustrate the need for consistent communication, and the importance, and difficulty of managing trust within and of the regulatory regime as a whole.

In sum, they illustrate that regulators have to be aware of and respond to limitations of the capacity and attitude of regulated firms, to the weaknesses of their own organisational structures and processes, to the pressures imposed by the market, legal and political context of the regulatory system as a whole, to the potential points of failure in the regulatory techniques being used, to knowledge and understandings of risks and markets, to the role of communication and trust throughout the regime, and to changes in each of these. ${ }^{67}$ The analysis also

\footnotetext{
${ }^{66}$ Ibid p.242.

${ }^{67}$ Baldwin, R and Black, J (2008), 'Really Responsive Regulation' 71(1) Modern Law Review 59-94.
} 
suggests where those who oversee regulators should be looking for potential points of failure, and to the varying ability that even independent regulators may have to counter the pressures that politicians can place on them. But above all, it shows that we need to learn from disasters, wherever they happen around the world. In doing so we will not prevent them from happening again, but we could reduce their likelihood. 